\title{
The evolution and performance of the Henderson Mine's C-arch shotcrete drawpoint support
}

NA Shea Climax Molybdenum Co., USA

\begin{abstract}
For over 30 years, the Henderson Mine used varying styles of steel and concrete drawpoint support in its panel caving operation. In 2007, a radical departure from the traditional brow was first tested. This ' $C$-arch' drawpoint was built with shotcrete and used cable bolts to secure the in situ rock to act as a brow. This dramatic change was a major reduction in the effort and materials required to build the drawpoint, but time was required to understand the performance under draw conditions.

Based on the performance of the first few test drawpoints, the C-arch was used in the final portion of the 7210 Main production panel with positive results. Subsequently, the current production panel, known as the 7700 Southwest (SW) panel, was developed entirely with C-arch drawpoints.

Midway through the development of the 7700 SW panel, the C-arch design was updated. This update simplified the surface support installation to improve the efficiency and quality of the surface support.

The 7700 SW panel is now in a fully mature stage of production. Data has been collected on the wear characteristics of nearly 200 drawpoints on the panel over several years. This provides the first opportunity for analysis of the performance of the C-arch across a full production panel, from cave initiation to maturity.

Data analysis provides insight into factors that influence the wear performance of the C-arches. In addition, the data supports the design change made mid-panel, and the continued use of C-arches for drawpoint support.
\end{abstract}

Keywords: ground support, drawpoint, brow, extraction level

\section{Introduction}

The Henderson molybdenum mine has been operating as a post-undercut, continuous panel caving operation since 1976. The extraction level drawpoint brows were supported using various styles of steel and cast-in-place concrete shells for over 30 years as the mine progressed through extraction levels at increasing depth. These worked well through the first two extraction levels located at depths of 1,280 and 1,400 m below surface. As design work began on the lowest extraction level 1,550 m below surface, the 7210 level, steel brows were considered essential to withstand the induced abutment stresses (Rech et al. 2000) and to provide the required brow stability to maintain effective flow control from the drawpoint.

Traditional steel and concrete brows were installed on the 7210 level as caving began in 2005. Early in the caving process, it was recognised that this lowest level would require modification of support practices from the previous 7700 level (Golden \& Fronapfel 2008). Weak ground and increased depth resulted in increased deformation on the extraction level, including in the drawpoint brow. The steel in the brows would buckle under abutment loading prior to substantial production. The initial response to this brow damage was to increase the steel support, with up to three additional steel arch sets in addition to the brow. However, damage continued to occur with abutment loading (Figure 1). This resulted in significant repair effort, including installing new steel sets and cast-in-place concrete after abutment loading (Golden \& Fronapfel 2008). 


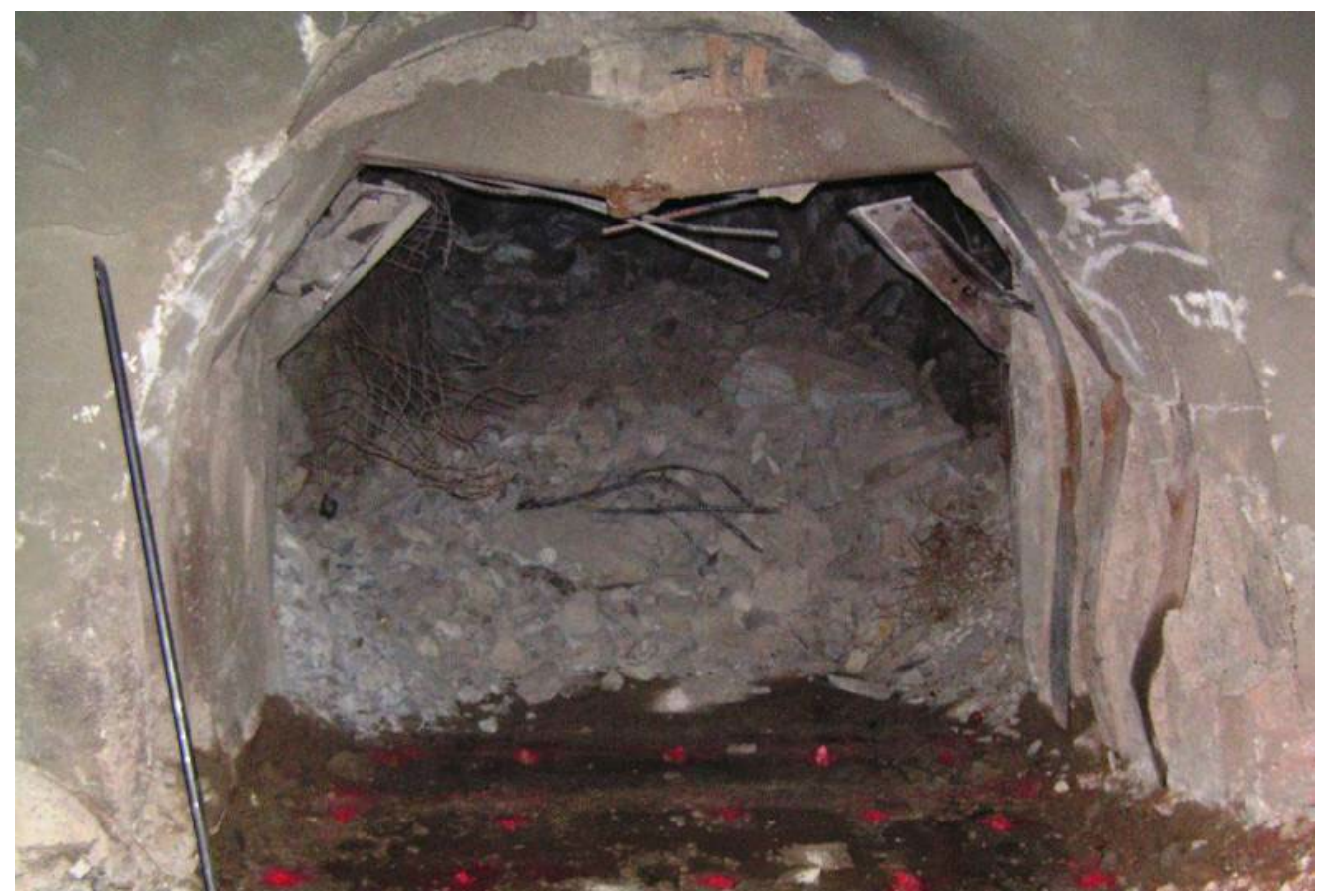

Figure 1 Drawpoint damage after abutment loading on the 7210 level. The brow set and arch support legs are buckled (Johnson \& Loring 2010)

The operation was managing this deformation and repair cycle, while continuing to develop and cave the 7210 level, when a concept was seen in a site visit to the Sudbury basin that would change the approach to drawpoint support. The $\mathrm{C}$-arch concept uses grouted cable bolts to secure the in situ rock, rather than adding more steel and concrete underneath it. Reinforced shotcrete arches provide the surface brow support. To see if this reinforced shotcrete arch could handle the abutment loads, and subsequent production, the first Henderson C-arch design (Figure 2) was developed and tested in 2007.
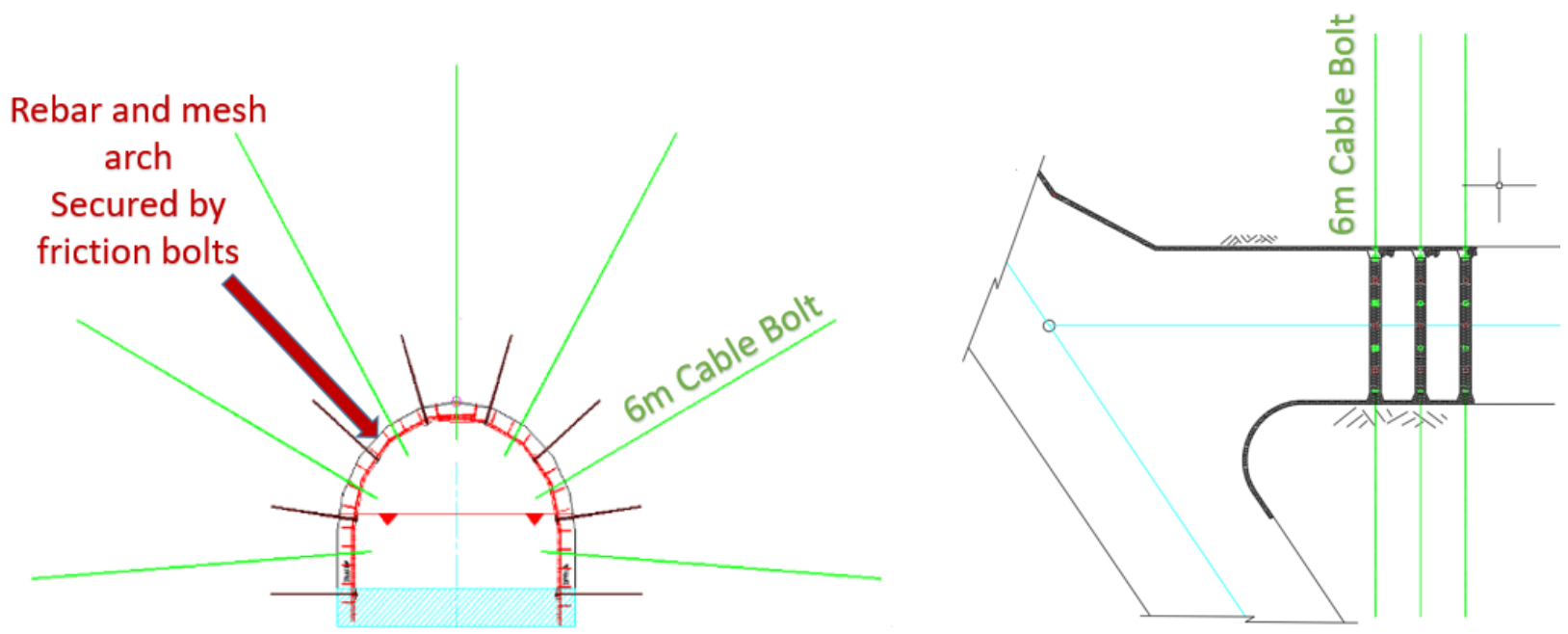

Figure 2 Initial C-arch support design; three rings of cable bolts are installed with a reinforced shotcrete arch for surface support

Drawpoints were mined to a smaller arch profile to leave as much rock in place as possible and to provide the necessary flow control for extraction. Then, three rings of $6 \mathrm{~m}$ cable bolts were installed with $1.2 \mathrm{~m}$ bolt spacing on $1.2 \mathrm{~m}$ ring spacing, in the normal brow location. Three rings were used with the assumption that two rings could wear and fail, leaving one in place to control muck flow. Following cable bolt installation, light re-bar frames were placed over the cables and shaped to fit the rock arch. Welded wire mesh was then placed 
over all three arch rings and secured in place with friction bolts (Figure 3). To complete the support, shotcrete was then placed on the entire structure, filling in the arch.

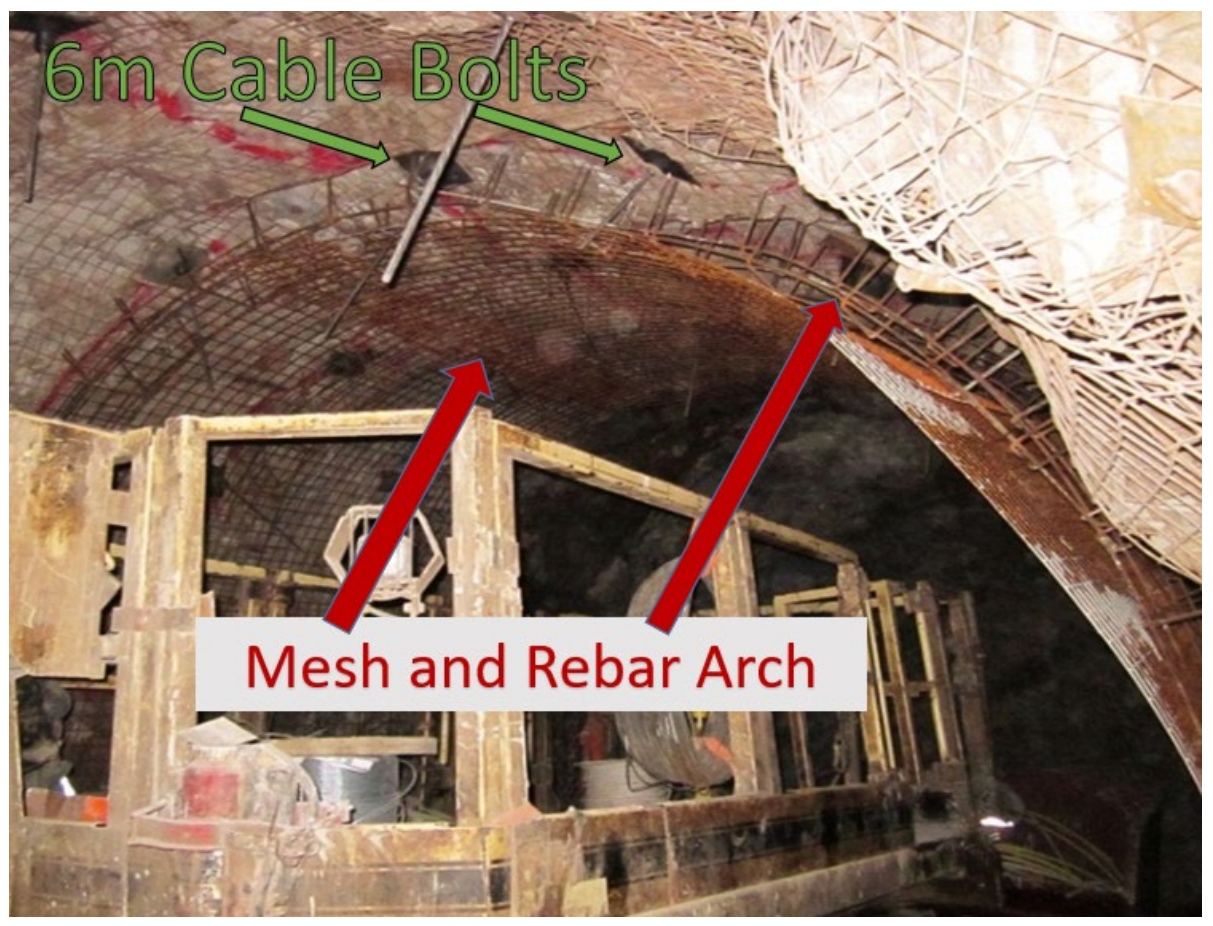

Figure 3 C-arch installation; welded wire mesh is placed on re-bar frames to form an arch below the three rings of cable bolts

With such a radical departure from heavy steel arch construction, testing proceeded cautiously. Initially, only two drawpoints on the fringe of the level were constructed with C-arches. These drawpoints performed well under abutment loading, with damage limited to cracking in the shotcrete. On the strength of the performance of these first two drawpoints, a second test group of five $\mathrm{C}$-arch drawpoints was constructed away from the fringe on the 7210 level. This test group also performed well, again showing only minor damage with abutment loading (Sainsbury \& Loring 2013). When more than $109,000 \mathrm{t}$ of ore had been successfully extracted from the first test drawpoints, the decision was made to install C-arches in the remaining 50 drawpoints on the 7210 level.

The initial C-arch design provided benefits in multiple areas. In addition to responding well to deformation, it provided safety and efficiency benefits over the traditional design. Safety risk was reduced during installation by eliminating the lifting of heavy components as well as the labour intensive, constricted concrete forming process. Operational safety risks were reduced by eliminating the need to remove or repair broken steel and concrete structures after they were damaged. Repair to the C-arches could be performed simply by applying additional shotcrete. Efficiency of the operation was increased through a dramatic reduction in the labour and materials required to construct the drawpoint (Johnson \& Loring 2010).

The safety and efficiency gains from the $\mathrm{C}$-arch design lead to the use of C-arches on the entire next production panel.

\section{Design update}

In this next production area, known as the 7700 Southwest (SW) panel, C-arch construction continued, with the design essentially unchanged since the first test drawpoint constructed in 2007. The design had performed well in difficult conditions on 7210 , and was expected to continue to perform well in the more competent rock found on the 7700 SW panel. In 2014, caving had begun on this new panel and approximately 80 drawpoints had been constructed when the first update to the $\mathrm{C}$-arch design since its inception was developed. 
With the start of caving on the 7700 SW panel, it was quickly observed that there was a large amount of oversized material and a high frequency of hangups in the drawpoints. Harder, more competent, rock had resulted in larger fragmentation with caving (Fuenzalida et al. 2017). At the same time, increased damage was seen in the $\mathrm{C}$-arches, even though overall deformation damage in the panel remained low. Opportunities to improve the $\mathrm{C}$-arch design began to be considered to ensure that the brows continued to perform as required.

Dr. Barton describes Rib Reinforced Shotcrete (RRS) arches used in modern versions of the Q-system to address poor ground conditions (Barton 1996). The similarities between RRS arches and C-arches led to opportunities for improvement identified from the RRS design. With RRS arches, shotcrete reinforcement is arranged in a flat section, using shotcrete layers to create the required thickness, additionally, rock reinforcement bolting is secured through the shotcrete reinforcement to create an interactive system (Figure 4).
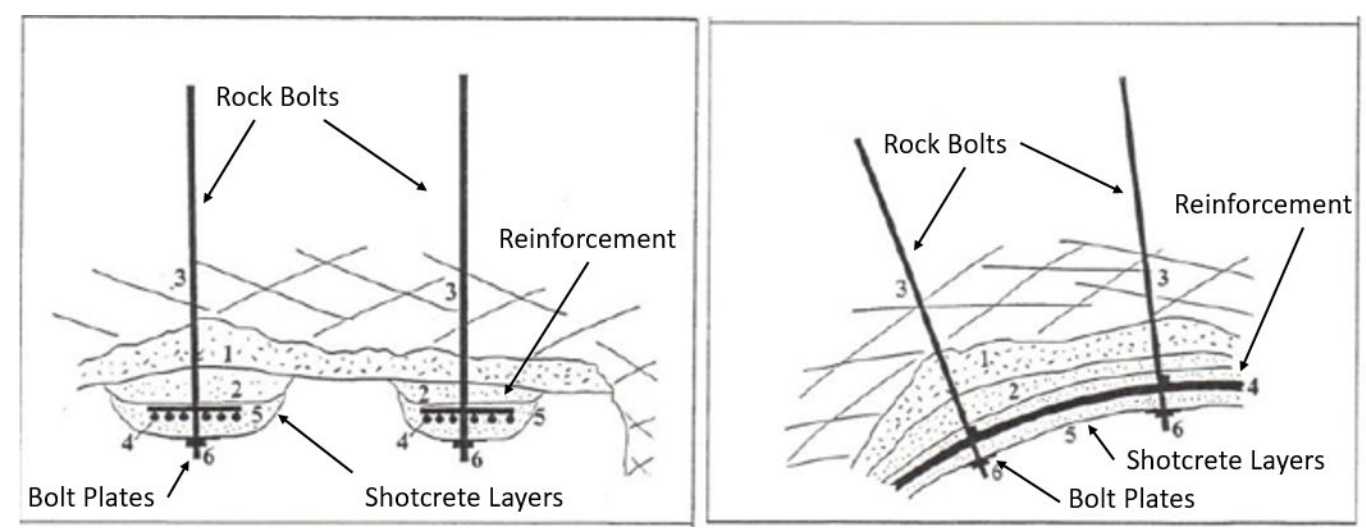

Figure 4 Rib Reinforced Shotcrete (RRS) arches (from Barton 1996); shotcrete layers create the required thickness, while rockbolting passes through the arch reinforcement to create an interactive system

Working with the operations group to develop the installation process, a new design was agreed upon which incorporated these features from the RRS arches. In this new design, dubbed the C-001 Arch, $100 \mathrm{~mm}$ of shotcrete is applied after drawpoint mining and primary support installation. Then, three rings of cable bolts are installed at the same $1.2 \mathrm{~m}$ spacing as in the original design. Next, $8 \mathrm{~mm}$ welded wire mesh straps, $45 \mathrm{~cm}$ wide, are secured with the cable bolt plates during cable bolt tensioning (Figure 5). A final pass of shotcrete covering the mesh straps completes the process.

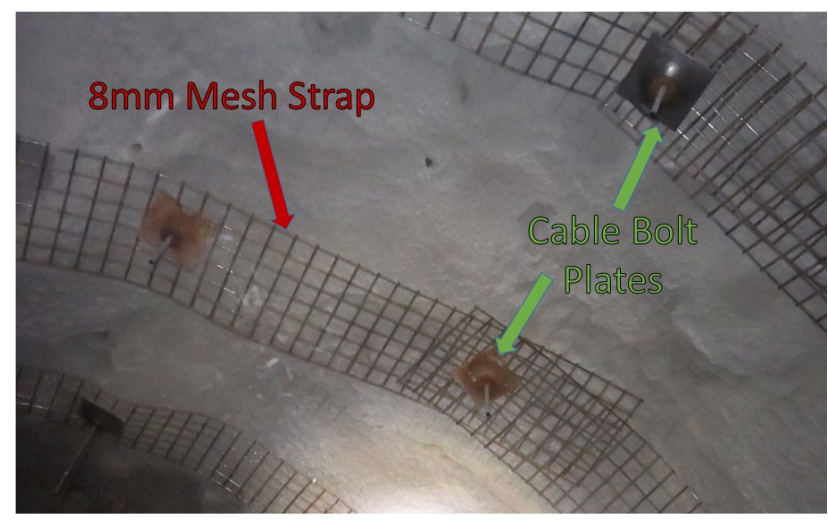

Figure 5 Arch reinforcement mesh straps in the updated C-001 arch design; initial shotcrete builds the arch thickness, cable bolt plates secure the arch straps, creating an interactive support system

Incorporating these basic features of the RRS system into the C-arch design resulted in benefits to the safety, efficiency and quality of the C-001 arch installation. Eliminating the hand tying of the rebar and mesh reduces safety risk and increases process efficiency by further reducing the manual work required to support the 
drawpoint. Installation quality is improved by eliminating the potential for voiding in the shotcrete behind the outer layer of welded wire mesh. By placing the mesh straps with the cable bolt plates, the surface support arch creates an interactive system with the rock reinforcement, increasing the effectiveness of both components.

The advantages of this update were quickly apparent, and the C-001 Arch was used for the remaining 120 drawpoints on the 7700 SW panel.

\section{Performance data}

With the design update, data was collected on the wear condition of the drawpoint brows across the panel. This data would be used to understand the effectiveness of the design update, and identify any conditions that may warrant further design modifications. Periodic observations of the brow condition were made in each drawpoint using a damage classification based on the condition of the three brow rings. As each ring was damaged or lost, the damage classification would increase as shown in Table 1.

Table 1 Empirical damage scale used to evaluate drawpoint surface wear

\begin{tabular}{ll}
\hline Brow condition & Description \\
\hline One - excellent & No damage, all rings intact \\
Two - very good & First brow ring damaged, but functional \\
Three - good & First brow ring lost, second ring intact \\
Four - fair & First brow ring lost, second ring damaged \\
Five - poor & First and second rings lost, final ring intact \\
Six - very poor & First and second ring lost, final ring damaged \\
Seven - extremely poor & All brow rings lost \\
\hline
\end{tabular}

Damage observations were made roughly twice per annum from 2014 to 2017 to understand the performance of the brows over time. The condition of the brows was then plotted on a map to identify problem areas and look for potential patterns in wear (Figure 6). From these maps, it was apparent that the drawpoints in the southern portion of the panel had more wear than those in the northern portion.

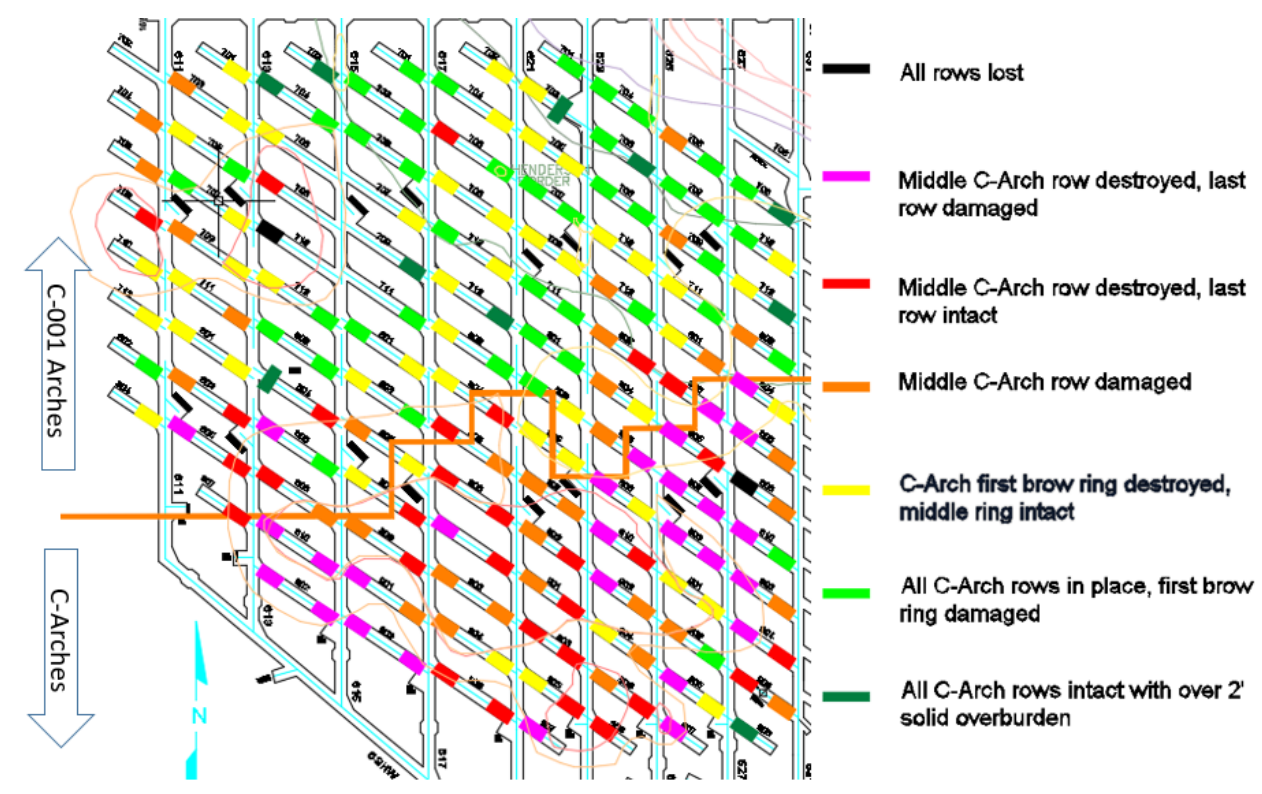

Figure 6 Observed drawpoint brow condition from December 2017; higher levels of wear are seen in the southern portion of the panel 
Several potential correlations warranted further investigation: the effects of the design update, the tonnage drawn through the drawpoints, the frequency of hangups, and the ground condition at the drawpoint.

\subsection{Design update}

As the most apparent potential correlation, the design change was investigated first. At the end of 2017, the average condition of the original C-Arch brows was 4.73, while condition of the C-001 updated arch design was 3.00. This indicates that the average C-001 arch had only lost one brow ring, while the original arches were likely to have lost two of the three brow rings. Overall, the updated design performed significantly better than the original design. Additional controlling factors were then investigated to understand their influence on this result.

\subsection{Tonnage drawn}

Brow wear data was compared to total tonnage extracted from the drawpoint. A simple correlation between brow wear rate and tonnage would be helpful in validating the effectiveness of the $\mathrm{C}$-arch over the lifespan of the drawpoints, and provide useful guidance for future designs. A scatter plot shows brow condition in relation to tonnes drawn from each drawpoint (Figure 7). As expected, an increase in damage was seen with increased tonnage drawn. However, the slope of the trend was shallow, and there was a wide scatter in the data. This indicates that there is not a simple linear relationship between tonnes drawn and brow wear.

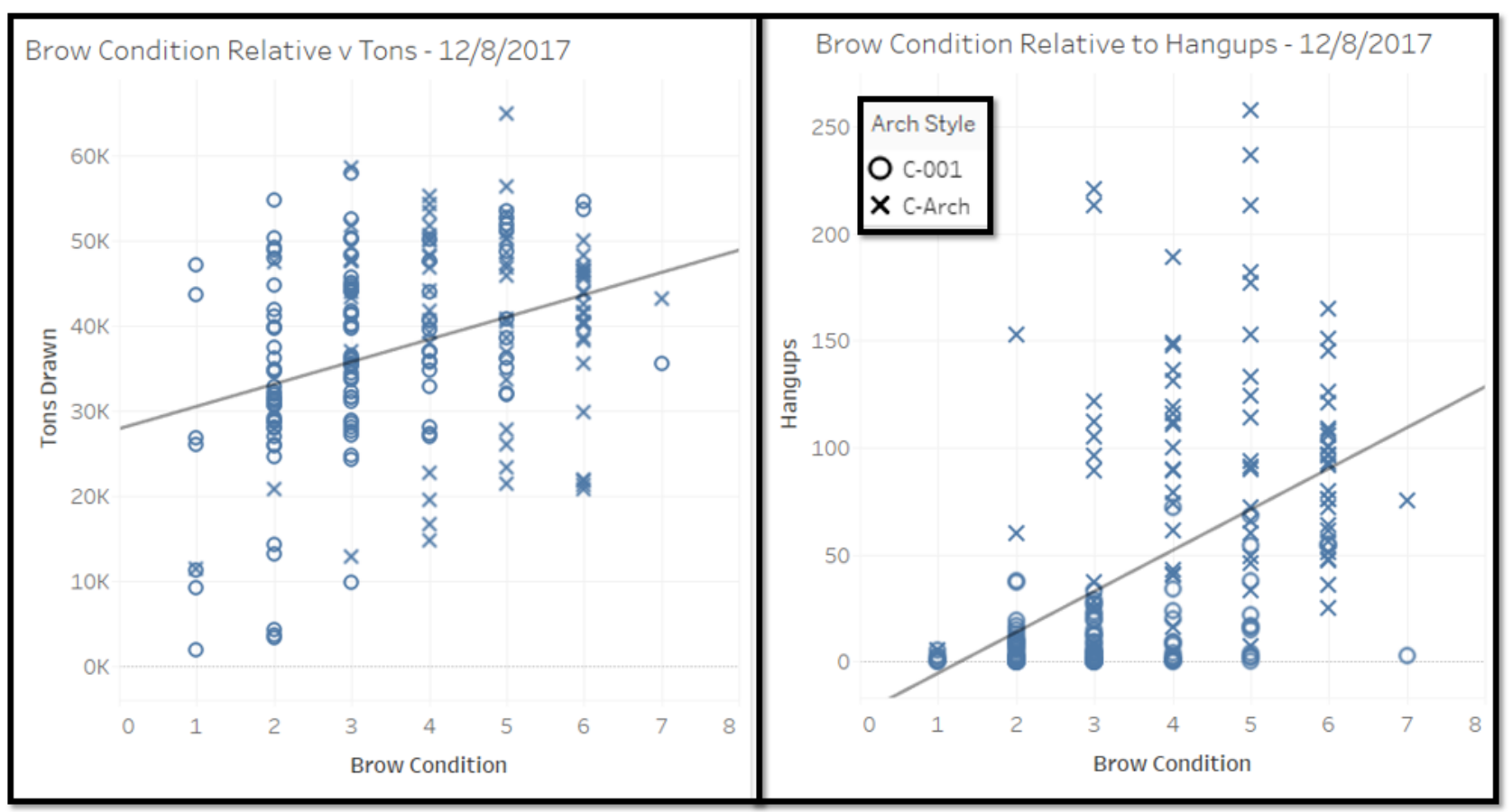

Figure 7 Observed drawpoint brow conditions relative to tons drawn and reported hangups. Hangups show a greater correlation to brow condition, with wide scatter in both datasets

\subsection{Hangups}

More wear could be expected in drawpoints with high frequency of hangups due to blasting damage as hangups were removed. Overall data showed a dramatically higher rate of hangups in the area of the original C-arch design. As of December 2017, approximately 7,500 hangups had been reported in the $80 \mathrm{C}$-arch drawpoints, compared to 1,000 in the C-001 Arches. The geometry of the two designs is too similar to effect a meaningful change in flow characteristics. However, as there was clearly an overall correlation between more hangups and more damage, data was again plotted against the drawpoint condition. Hangup frequency could be seen to have a greater influence on drawpoint wear than overall tonnage, but there was still a high degree of variability in the data, suggesting that hangups were not the only factor. 


\subsection{Ground conditions}

As the in situ rock effectively forms the brow with C-arch drawpoint, geology must be considered. In only two drawpoints on the panel were all three rings lost. In both of these cases, molybdenum faults at unfavourable angles had allowed the surface support to be sheared away from the brow. In both cases, enough rock was left in place that the drawpoint is in functional condition with repair. Alteration type can be used as an indicator of general rock mass quality as it influences the intact rock strength. Data collected from Henderson drillcore show compressive strengths ranging from $60 \mathrm{MPa}$ in weaker argillic altered rock to greater than $170 \mathrm{MPa}$ in harder potassic rock. Less altered 'normal' rock strength averages between 100 and $120 \mathrm{MPa}$. A combined histogram of drawpoint condition coloured by alteration type show the influence of alteration on brow performance (Figure 8). The C-001 arch performed very well in normal to softer conditions but less so in the harder conditions. The original C-arch design performed roughly the same across the range of alteration types, showing more wear than the C-001 arch in all conditions.

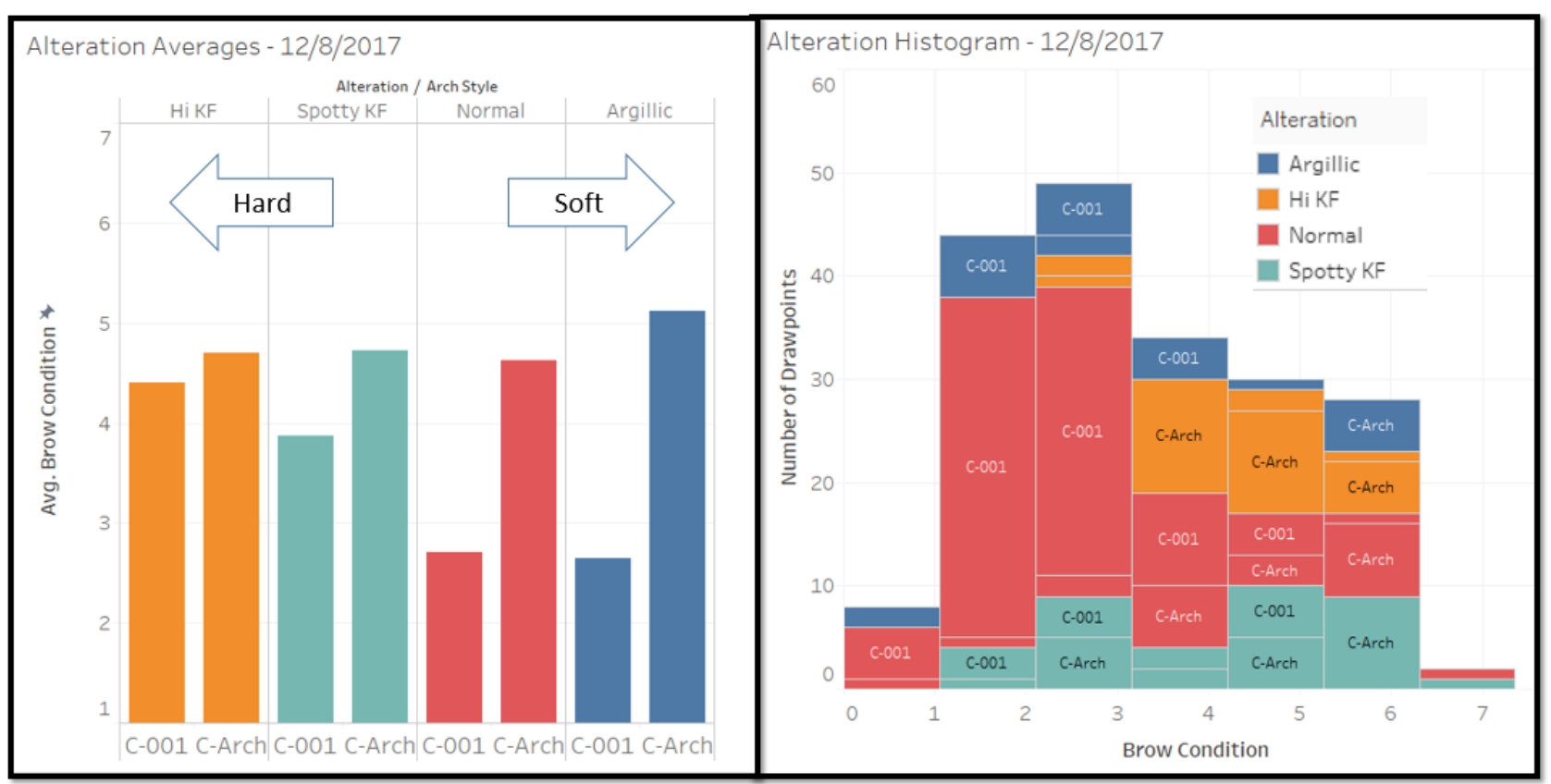

Figure 8 Brow condition related to alteration type. The original C-arch brow shows roughly equal damage across all alteration types. The C-001 updated arch style shows less overall damage, performing especially well in normal to softer alteration zones

The drawpoint condition data showed that that wear in the drawpoints was the result of complex interactions, and no single factor is a reliable indicator of drawpoint condition. Of the factors reviewed, arch style and hangup frequency showed the strongest relationship to drawpoint wear. To understand the performance of the drawpoints in terms of the planned production life of the panel, the data would need to be reviewed on a time scale.

\subsection{Performance over time}

With the complex nature of wear in the brows across the $7700 \mathrm{SW}$ panel, the critical performance factor is a sufficient degree of robustness to sustain planned production through the life of the panel.

In order to assess this, it was first necessary to look at the overall data as it was collected over the life of the panel. The brow condition data was then converted to rings lost to reduce ambiguity. There are three rings per drawpoint, and 600 total rings on the panel. By plotting observed rings lost per observation date with the total tons drawn from the panel (Figure 9), it is possible to see that the rate of damage is not a linear function. The majority of damage occurred between May 2015 and May 2016 during the cave initiation process, with the damage rate dropping dramatically after that point, even though tonnage drawn continues to increase. 
This indicates that much of the damage seen occurred early, and damage through the remaining life of the drawpoints will likely be minimal. By scaling this plot to the total number of rings on the panel and the total tons to be drawn, it is apparent that the total tonnage will be reached well before the brows are lost.

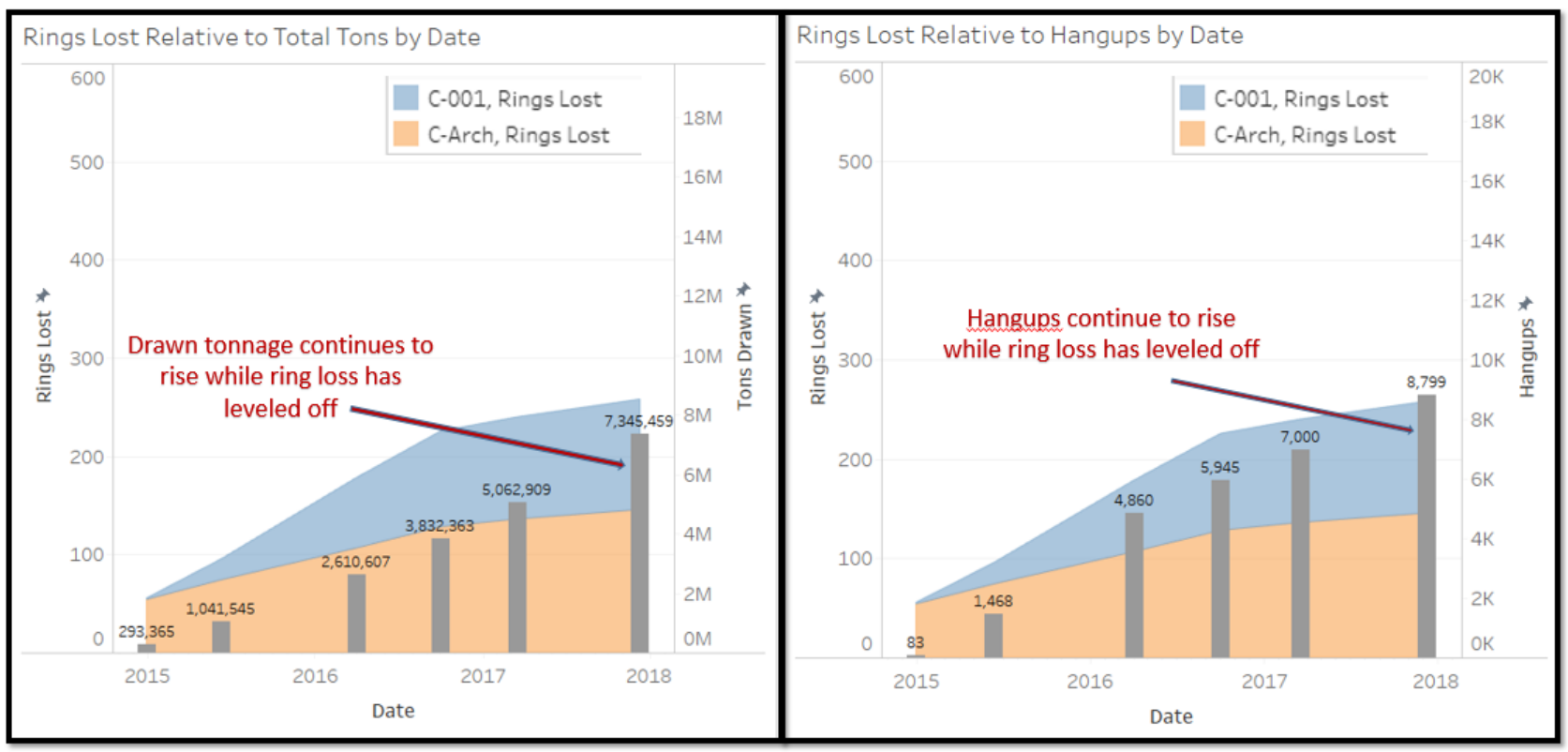

Figure 9 Rings lost over time compared to drawn tons and hangups. While draw and hangups continue, the rate of ring loss has slowed

The ring loss over time can also be compared to the hangups over time. Hangups over time better tracks the damage rate, with a reduction in hangup frequency after mid-2016. However, it does not track exactly, with some damaged brows seen early on, before a substantial number of hangups. In later periods, hangups continue at a greater frequency than is reflected in the brow damage data. This supports the analysis that additional factors beyond hangup frequency contributed to drawpoint wear, especially in early periods. Some factors that could not be captured but would affect early performance would be bell development blasting, abutment loading, fragmentation, and installation quality.

The final plot shows the overall condition of brows across the panel at the last observation date (Figure 10). This plot groups drawpoints by condition in terms of rings lost out of three, showing the number of drawpoints in each condition by arch type. From this plot it can be seen that a majority of drawpoints are in good to fair condition, with two brow rings remaining. Of the drawpoints in good condition, most are the updated C-001 arch. With the low rate of new damage, and the generally good condition of the drawpoints, they are expected to continue to perform through the life of the panel.

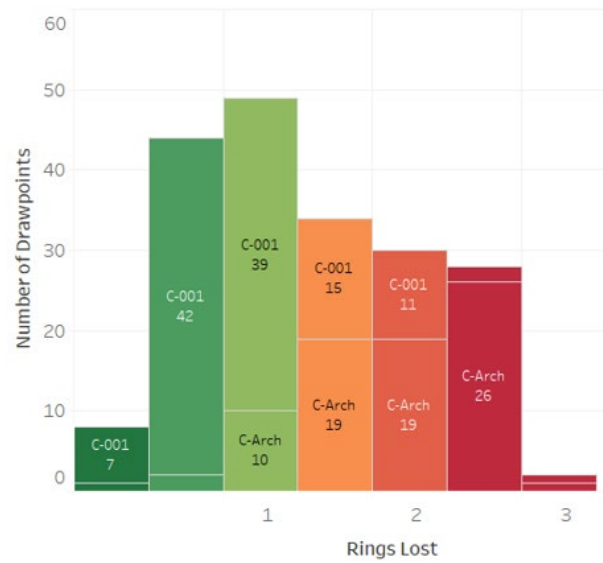

Figure 10 Overall brow condition at the end of 2017. Most of the brows are in good to fair shape with two brow rings remaining. Of the brows in good condition, most are the updated C-001 arch design 


\section{Conclusion}

The C-Arch drawpoint, and the subsequent design update, have been successful at the Henderson mine. They have brought safety and efficiency benefits to the operation and performed well in a variety of conditions. Observations of the original and updated design show that the multiple factors influence the wear performance of the drawpoint brows, most notably hangup frequency and brow design. Given the complex nature of brow wear, the updated C-001 Arch has performed well in a variety of conditions, performing especially well in normal alteration and draw conditions. As a safer and more efficient way to support the drawpoint, C-Arches, specifically the updated C-001 design, are the planned drawpoint support for the future at the Henderson mine.

\section{Acknowledgement}

The work of Jordan Hildreth in compiling and formatting the production and hangup data to be compared with the brow condition data is appreciated.

\section{References}

Barton, N 1996, 'Investigation, design, and support of major road tunnels in jointed rock using NMT principles', Proceedings of the IX Australian Tunnelling Conference: Breaking New Ground, Australian Underground Construction and Tunnelling Association, Institution of Engineers, pp. 145-159.

Fuenzalida, M, Katsaga, T \& Pierce, M 2017, Analysis of Cave Propagation and Drift Closure in 7700SW Panel, unpublished report, Itasca International, Inc., Minneapolis.

Golden, R Jr. \& Fronapfel, L 2008, 'Evolution of ground support practices on Henderson's lower levels', in H Schunnesson \& E Nordlund (eds), Proceedings of the Fifth International Conference and Exhibition on Mass Mining, The Australasian Institute of Mining and Metallurgy, Melbourne, pp. 717-728.

Johnson, W \& Loring, DM 2010, 'New browless support of a draw bell at the Henderson Mine', presentation for the 2010 SME Annual Meeting, Denver.

Rech, WD, Keskimaki, KW \& Stewart, DR 2000, 'An update on cave development and draw control at the Henderson Mine', in G Chitombo (ed.), Proceedings of the International Conference and Exhibition on Mass Mining (MassMin 2000), The Australasian Institute of Mining and Metallurgy, Melbourne, pp. 495-505.

Sainsbury, DP \& Loring, DM 2013, 'Analysis of extraction level performance at the Henderson Mine', in Y Potvin \& B Brady (eds), Proceedings of the Seventh International Symposium on Ground Support in Mining and Underground Construction, Australian Centre for Geomechanics, Perth, pp. 539-550. 
